\title{
1 Functional correlates of immediate early gene expression in mouse visual cortex
}

2 David Mahringer ${ }^{1,2}$, Pawel Zmarz ${ }^{1,2,3}$, Hiroyuki Okuno ${ }^{4}$, Haruhiko Bito ${ }^{5}$ Georg B. Keller ${ }^{1,2,6}$

$3 \quad{ }^{1}$ Friedrich Miescher Institute for Biomedical Research, Basel, Switzerland.

$4 \quad{ }^{2}$ Faculty of Natural Sciences, University of Basel, Basel, Switzerland.

$5{ }^{3}$ Current address: Department of Organismic and Evolutionary Biology and Center for Brain Science, 6 Harvard University, Cambridge, MA 02138, USA.

$7 \quad{ }^{4}$ Department of Biochemistry and Molecular Biology, Kagoshima University Graduate School of Medical

8 and Dental Sciences, Kagoshima, Kagoshima 890-8544, Japan.

$9{ }^{5}$ Department of Neurochemistry, Graduate School of Medicine, The University of Tokyo, Hongo 7-3-1,

10 Bunkyo-ku, Tokyo 113-0033, Japan.

$11 \quad{ }^{6}$ Correspondence to: georg.keller@fmi.ch

The expression of immediate early genes (IEGs) in visual cortex can be triggered by visual input and is associated with certain forms of neuronal plasticity. How IEG expression in cortical neurons relates to neuronal activity or experience-dependent changes of neuronal activity, however, is still unclear. Using three transgenic mouse lines that express GFP under the control of different IEG promoters (cfos, egr1 or Arc), we recorded both neuronal activity and IEG expression levels in primary visual cortex before and after a mouse's first visual exposure, and subsequent visuomotor learning. We found that expression levels of all three IEGs correlated positively with neuronal activity, and that different IEGs are preferentially expressed in different functional cell types. Neurons with strong motor-related activity preferentially expressed EGR1 while neurons that developed strong visually driven activity preferentially expressed Arc. Our findings suggest that during functional development of visual cortex different IEGs are preferentially expressed in neurons that receive different functional types of input.

\section{INTRODUCTION}

Ever since the discovery that the expression of the transcription factor c-Fos can be induced by electrical or chemical stimulation in neurons (Greenberg and Ziff, 1984), the expression of immediate early genes (IEGs) has been used as a marker for neuronal activity (Bullitt, 1990; Guzowski et al., 1999; Jarvis et al., 2000; Knapska and Kaczmarek, 2004; Minatohara et al., 2015; Morgan et al., 1987; Ramírez-Amaya et learning (Chowdhury et al., 2006; Fleischmann et al., 2003; Gandolfi et al., 2017; Jones et al., 2001; 
Messaoudi et al., 2007; Rial Verde et al., 2006; Shepherd and Bear, 2011; Shepherd et al., 2006;

Tzingounis and Nicoll, 2006; Vazdarjanova et al., 2006; Veyrac et al., 2014; Waung et al., 2008) and are necessary for long-term memory consolidation (Bozon et al., 2003; Fleischmann et al., 2003; Guzowski, 2002; Guzowski and McGaugh, 1997; Guzowski et al., 2000; Jones et al., 2001; Ploski et al., 2008; Yasoshima et al., 2006). In addition it has been shown that certain forms of episodic memory can be reactivated by artificially activating an ensemble of neurons characterized by high IEG expression levels during memory acquisition (Denny et al., 2014; Garner et al., 2012; Liu et al., 2012; Ramirez et al., 2013). Based on this, it has been speculated that IEG expression is related not simply to neuronal activity per se, but to the induction of activity-dependent plasticity (Holtmaat and Caroni, 2016; Josselyn et al., 2015). It is still unclear, however, how IEG expression relates to neuronal activity in vivo, and whether IEGs are preferentially expressed in neurons that undergo plasticity. Here we characterize IEG expression in relation to neuronal activity in layer $2 / 3$ neurons of mouse primary visual cortex during the mouse's first visual exposure and subsequent visuomotor learning. During visuomotor learning, visual feedback from self-generated movement is thought to shape bottom-up visual input and top-down motor-related input onto layer $2 / 3$ neurons in visual cortex such that neurons are differentially driven by the two inputs (Attinger et al., 2017; Leinweber et al., 2017). To quantify how IEG expression correlates with neuronal activity and whether IEGs are differentially expressed in neurons that develop different functional response types during visuomotor learning, we simultaneously recorded neuronal activity and IEG expression in layer $2 / 3$ of primary visual cortex during first visual experience and subsequent visuomotor learning.

\section{RESULTS}

To quantify both IEG expression levels and neuronal activity chronically, we used a combination of transgenic mice that express GFP under the control of an IEG promoter and viral delivery of a red variant of a genetically encoded calcium indicator. We did this for three different IEGs (c-fos, egr1, and Arc), in three groups of mice separately. EGFP-Arc and c-Fos-GFP mice are transgenic mice that express a fusion protein of Arc or c-Fos, and GFP, downstream of either an Arc or a c-fos promoter, respectively (Barth et al., 2004; Okuno et al., 2012), while the EGR1-GFP mouse expresses GFP under an egr1 promotor (Xie et al., 2014). Although there are a number of caveats to using GFP levels in these mouse lines as a proxy for IEG expression levels (see discussion), there is a strong overlap between post-mortem antibody staining

61 for the respective IEG and GFP expression in all three mouse lines (Barth et al., 2004; Okuno et al., 2012;

62 Xie et al., 2014; Yassin et al., 2010). Throughout the manuscript we will use IEG expression to mean GFP 
expression levels in these mice. To measure neuronal activity in layer $2 / 3$ of primary visual cortex, we used an AAV2/1-Ef1a-jRGECO1a viral vector to express the red calcium indicator jRGECO1a (Dana et al., 2016). These activity measurements are biased towards excitatory neurons, as in the first few weeks after the injection, the Ef1a promoter restricts expression mainly to excitatory neurons (Attinger et al., 2017).

To quantify the correlation between neuronal activity and IEG expression in layer $2 / 3$ of visual cortex in adult mice, we first used a paradigm of dark adaptation and subsequent brief visual exposure (Figure 1A). We did this in three groups of adult mice separately (4 EGFP-Arc mice, 4 c-Fos-GFP mice, and 4 EGR1-GFP mice, all mice were between 100 and 291 days old). We dark-adapted all three groups of mice for 24 hours and subsequently head-fixed them, while still in complete darkness, under a two-photon microscope on a spherical treadmill (Figure 1A). We then measured calcium activity and IEG levels every 15 minutes for six hours (Figures 1B-1D; see Methods). Between the first and second measurement, mice were exposed to visual input for 15 minutes. This paradigm, which is a combination of light exposure and exposure of the mouse to head-fixation, resulted in transient increases in Arc and EGR1 expression levels, and a decrease in c-Fos expression levels (Figure S1A). We then computed the correlation between average neuronal activity and IEG expression levels as a function of time between neuronal activity measurement and IEG expression measurement (Figures 1E-1G). Correlation peaked at a time lag of approximately $3.5 \mathrm{~h} \pm 0.5 \mathrm{~h}$ (mean \pm SEM) between neuronal activity measurement and IEG measurement for Arc and c-Fos, and was relatively stable in a window from -2 hours to +3 hours for EGR1 (Arc: 1382 neurons, c-Fos: 1070 neurons, EGR1: 1319 neurons; Figures 1E-1G). At peak, the correlation between neuronal activity and IEG expression was highest for c-Fos, intermediate for Arc, and lowest for EGR1 (Figures 1H-1J; correlation coefficients for c-Fos: $0.39 \pm 0.07$, Arc: $0.26 \pm 0.05$, EGR1: $0.21 \pm 0.03$, mean \pm SEM; comparisons between c-Fos vs. Arc: $p<3 \times 10^{-4}$, Arc vs. EGR1: $p=$ 0.0188 , c-Fos vs. EGR1: $p<10^{-8} ; 4$ mice per group, t-test with bootstrapping, see Methods). The positive correlation and the time lag of the correlation peak would be consistent with the idea that neuronal activity induces IEG expression, but the fact that correlations with mean activity were relatively weak could mean that it is specific patterns or types of activity that induce IEG expression.

It is often assumed that IEG expression is also a correlate of neuronal plasticity (Holtmaat and Caroni, 2016; Josselyn et al., 2015; Kaplan et al., 1996). Changes in the expression levels of immediate early genes during learning have been associated with events of neuronal plasticity in vivo (Mahringer et al., 2019; Minatohara et al., 2015). Given that certain forms of neuronal plasticity are associated with bursts 
of activity, we first tested whether maximum activity was a better predictor of IEG expression levels than mean activity. Indeed, we found that the correlation with maximum neuronal activity was higher than the correlation with mean activity for all three IEGs, but only significantly so for Arc and EGR1 (Figure S1B). Given that IEG expression could be related to neuronal plasticity, we speculated that the induction of expression could depend on the source of the drive of the neuronal activity, and that the different IEGs are expressed differentially in response to different types of input. c-Fos and EGR1 expression levels in visual cortex, for example, are differentially regulated by visual experience and exhibit a differential dependence on neuromodulatory input (Yamada et al., 1999). In addition to visual input, visual cortex is driven by several non-visual types of input, most prominently by locomotionrelated input (Keller et al., 2012; Saleem et al., 2013). Visual responses are predominantly driven by bottom-up thalamic input, while motor-related responses are thought to be driven by top-down, long range cortical input (Leinweber et al., 2017). We have speculated that individual excitatory neurons in layer $2 / 3$ of visual cortex are differentially driven by these two types of inputs (Attinger et al., 2017).

107 To investigate whether the drive of activity influences IEG expression, we set out to quantify correlations between IEG expression levels and different functional types of neuronal activity during development at a time when first visuomotor experience shapes the functional responses in layer $2 / 3$ excitatory neurons (Attinger et al., 2017). We reared mice in complete darkness and quantified both IEG expression levels

111 and neuronal activity before and after mice were exposed to visual input for the first time in life as well 112 as during a subsequent phase of visuomotor learning. Under normal conditions, first visual exposure is 113 coincident with exposure to normal visuomotor coupling. At eye opening, mice are capable of moving 114 eyes, head, and body and thus immediately experience self-generated visual feedback. In order to 115 experimentally separate the moment of first visual exposure from first exposure to normal visuomotor 116 coupling, we recorded neuronal activity and IEG expression as mice transitioned through three different 117 experimental conditions. Prior to experiments, three groups of mice were reared in complete darkness 118 until postnatal day 40 (7 EGFP-Arc mice, 5 c-Fos-GFP mice, and 4 EGR1-GFP mice). We then imaged 119 neuronal activity and IEG expression levels every 12 hours for a total of 6 days. During all two-photon 120 imaging experiments, mice were head-fixed on a spherical treadmill. During the first four recording 121 sessions mice were kept on the setup in darkness to measure locomotion-related and non-visual activity 122 and remained dark housed in between recording sessions (condition 1). At the beginning of the $5^{\text {th }}$ 123 recording session, mice were then exposed to visual input for the first time in their life. In the 124 subsequent four recording sessions, mice were exposed to different phases of visuomotor coupling in a 125 virtual environment but remained housed in darkness in the time between the recording sessions 
126 (condition 2). In addition to recording activity in darkness, recording sessions in condition 2 also

127 contained 8 min of closed-loop feedback during which visual flow on the walls of a virtual corridor was

128 coupled to the mouse's locomotion on the spherical treadmill. During closed-loop feedback, we added

129 brief halts of visual flow to probe for visuomotor mismatch responses (Keller et al., 2012). This was

130 followed by a phase of open-loop feedback during which the visual flow generated by the mouse during

131 the closed-loop feedback was replayed independently of the locomotion of the mouse. Lastly, we

132 presented a series of drifting gratings to the mouse to quantify visual responses (see Methods).

133 Following recording session 8, mice were introduced to a normal $12 \mathrm{~h}$ light / $12 \mathrm{~h}$ dark cycle. At this

134 time, mice first experienced normal visuomotor coupling in their home cage. We continued recording

135 for an additional four sessions (condition 3) with the same series of closed-loop, open-loop and grating

136 stimulation phases as in condition 2 (Figure 2A). Recording sessions lasted on average $12 \mathrm{~min} \pm 0.5 \mathrm{~min}$

137 (mean \pm SEM) in condition 1 , and $83 \min \pm 1 \min$ (mean \pm SEM) in conditions 2 and 3 (Figure S2).

138 It has been shown that visual input can drive the expression of different IEGs in a subset of neurons in

139 visual cortex (Kaminska et al., 1996; Kawashima et al., 2013; Rosen et al., 1992; Tagawa et al., 2005;

140 Wang et al., 2006). Based on this it is sometimes assumed that exposure to visual input increases

141 average neuronal activity in visual cortex. To test whether first visual exposure or first exposure to

142 normal visuomotor coupling results in an increase of average neuronal activity in visual cortex, we

143 quantified average neuronal activity in each recording session (in condition 1 this only included

144 recordings in darkness, while in conditions 2 and 3 this included recordings in darkness, closed and open-loop feedback, as well as drifting gratings). Consistent with a strong motor-related drive in visual cortex (Keller et al., 2012; Saleem et al., 2013) and rapid homeostatic restoration of average activity

147 following removal of visual input (Keck et al., 2013), we found no evidence of an increase of average neuronal activity at the onset of either condition 2 (first visual exposure) or condition 3 (first exposure to normal visuomotor coupling) (Figure 2B). To the contrary, following the first visual exposure, there was a trend for decreasing activity levels $\left(p=0.0293, R^{2}=0.371\right.$, linear trend analysis, see Methods). We next quantified average expression of Arc, c-Fos and EGR1 over the same time course. Consistent with

152 the absence of a change in average activity levels, we found no significant changes in the expression 153 levels of any of the three IEGs following the first visual exposure at the beginning of condition 2 (Figure 154 2C). Note, we cannot exclude that there is a transient increase in IEG expression between $1 \mathrm{~h}$ and $12 \mathrm{~h}$ 155 following first visual exposure, as we only recorded for 1 hour every 12 hours. We did however find that 156 the first exposure to normal visuomotor coupling at the beginning of condition 3, resulted in an increase 157 in the expression of Arc and a decrease in the expression of EGR1 in the absence of a measurable 
change in average neuronal activity levels (Figure 2C). To test for changes in the pattern of IEG expression that are not detectable by mean population expression, we quantified the similarity of IEG expression patterns by computing the correlation of IEG expression vectors between imaging time points (see Methods). We found that the pattern of Arc expression changed both with the first visual exposure (onset of condition 2) and the first exposure to normal visuomotor coupling (onset of condition 3) (Figure 2D). The pattern of c-Fos expression exhibited no detectable discontinuous changes (Figure 2E), while the pattern of EGR1 expression exhibited a marked transition with the first exposure to normal visuomotor coupling (onset of condition 3) (Figure 2F). This suggests that the expression patterns of IEGs are differentially and dynamically regulated by visuomotor experience, also in absence of population mean expression level changes.

Neurons in layer $2 / 3$ of primary visual cortex are driven differentially by visual and motor-related inputs (Attinger et al., 2017; Keller et al., 2012; Leinweber et al., 2017). Given that the expression patterns of the three IEGs are differentially altered by first visual exposure and first exposure to normal visuomotor coupling, we speculated that the different IEGs could be preferentially expressed in different functional types of excitatory neurons in layer $2 / 3$. Neurons that are more strongly visually driven, likely by bottom-up visual input, could have a different IEG expression profile than neurons that are more strongly driven by top-down motor-related signals (Leinweber et al., 2017; Makino and Komiyama, 2015). To test this, we quantified the functional properties of the neurons with the highest IEG expression levels immediately after the first exposure to normal visuomotor coupling where we observed the largest mean IEG expression level changes (Figure $\mathbf{2 C}$ ). We selected the $10 \%$ of neurons with the highest Arc, c-Fos and EGR1 expression, respectively, at the beginning of condition 3 (Arc: 197 neurons, c-Fos: 189 neurons, EGR1: 121 neurons) and tested whether these neurons were more strongly driven by visual or motor-related input. As a measure of the strength of the motor-related input, we used the magnitude of the neuronal response during running onsets in darkness. We found that neurons with high EGR1 expression levels developed higher motor-related responses than the rest of the population in both condition 2 and condition 3. Conversely, neurons with high Arc expression levels developed motor-related responses that are lower than the rest of the population following exposure to normal visuomotor coupling. Responses in neurons with high c-Fos expression levels were not different from responses in the rest of the population (Figure 3A). To quantify the strength of visual input we used the magnitude of the neuronal response to drifting grating stimuli. Consistent with the fact that Arc expression can be selectively induced by visual stimuli in a stimulus-specific manner (Kawashima et al., 2013), we found that neurons with high Arc expression levels developed responses to drifting grating 
stimuli that were stronger than the rest of the population after exposure to normal visuomotor coupling. The drifting grating responses of neurons with high EGR1 or c-Fos expression levels were not different from the mean population response (Figure 3B). Thus, neurons with high levels of EGR1 expression after first exposure to normal visuomotor coupling were more strongly driven by motorrelated input, while those with high levels of Arc expression were more strongly driven by visual input.

One of the signals that has been speculated to be computed in mouse primary visual cortex that combines visual and motor-related input is sensorimotor mismatch (Attinger et al., 2017; Keller et al., 2012; Zmarz and Keller, 2016). Neurons that respond to mismatch, or negative prediction errors, are thought to receive excitatory motor-related input and inhibitory visual input (Attinger et al., 2017; Keller and Mrsic-Flogel, 2018). We speculated that given the increased motor-related activity in neurons that express high levels of EGR1, neuronal activity in these neurons should correlate positively with running, while activity in neurons that express high levels of Arc should correlate positively with visual flow. To quantify this, we computed the correlation of neuronal activity with either running or visual flow during the open-loop phases in conditions 2 and 3 for the three groups of neurons with high IEG expression levels. We found that the activity of neurons expressing high levels of EGR1 correlated most strongly with running, while the activity of neurons with high levels of Arc expression correlated positively with visual flow (Figure 4A). Consistent with this we found that sensorimotor mismatch responses were larger in neurons with high EGR1 expression than in the rest of the population, while they were lower in neurons with high Arc expression than in the rest of the population (Figure 4B). This indicates that, at the onset of normal visuomotor coupling, EGR1 is preferentially expressed in mismatch neurons or, more generally, in neurons that are driven by excitatory top-down input, while Arc is preferentially expressed in neurons that are driven by bottom-up visual input.

\section{DISCUSSION}

It is well established that both neuronal activity and plasticity are linked to the expression of immediate early genes (Dudek, 2008; Minatohara et al., 2015; Yap and Greenberg, 2018). Comparably little, however, is known about how specific functional characteristics of neurons relate to the expression of immediate early genes. Here we investigated the relationship between the expression of three IEGs (Arc, c-Fos, and EGR1) and functional responses in excitatory layer 2/3 neurons of mouse visual cortex. We found that during visuomotor learning following a mouse's first visual exposure in life, Arc was preferentially expressed in neurons that are driven by excitatory bottom-up visual input, while EGR1 was preferentially expressed in neurons that are driven by motor-related input. In addition, we found that 
221

222

223

224

225

226

227

228

229

230

231

232

233

234

235

236

237

238

neurons expressing high levels of EGR1 exhibit visuomotor mismatch responses higher than the rest of the population, while neurons expressing high levels of Arc exhibit visuomotor mismatch responses weaker than the rest of the population.

Such a relationship between a neuron's IEG expression profile and its functional properties could be explained by differences in the contribution of different IEGs to different types of input synapses. Arc, cFos, and EGR1 all have unique cellular functions, and it is conceivable that they make different contributions to different synapse types. Genes for a subset of $\mathrm{GABA}_{A}$ receptor subunits, for example, are transcriptional targets of EGR1 (Mo et al., 2015). If the postsynaptic subunit composition of the GABA receptor is correlated with the presynaptic inhibitory cell type, EGR1 expression could preferentially upregulate specific inhibitory input pathways. Similar input pathway-specific roles have been described for other IEGs. Neuronal activity-regulated pentraxin (NARP) is secreted by pyramidal neurons and exclusively accumulates at parvalbumin-positive inhibitory neurons where it regulates excitatory synapses onto these cells (Chang et al., 2010; Gu et al., 2013). The activity-dependent transcription factor NPAS4 has been found to restrict the number of synapses of mossy-fiber input specifically onto CA3 pyramidal cells during learning (Weng et al., 2018). Consistent with a pathwayspecific expression of Arc and EGR1 in visual cortex, it has been shown that Arc is necessary for different forms of plasticity of bottom-up visual input, including ocular dominance plasticity (Gao et al., 2010; Jenks et al., 2017; McCurry et al., 2010; Wang et al., 2006), while a knockout of egr1 has been shown to leave ocular dominance plasticity unaffected (Mataga et al., 2001).

Our data would be consistent with the interpretation that the IEG expression pattern of a given neuron correlates with its pattern of synaptic inputs. Neurons that predominantly receive excitatory bottom-up drive likely require a different distribution and type of input synapses compared to neurons that receive mainly top-down excitatory drive. Layer $2 / 3$ neurons that exhibit strong motor-related and mismatch responses are thought to be driven by top-down excitatory inputs (Leinweber et al., 2017), which predominantly target apical dendrites (Petreanu et al., 2009). Conversely, layer $2 / 3$ neurons with strong visual responses are thought to be driven by bottom-up visual inputs, which predominantly target basal dendrites (Petreanu et al., 2009). We have speculated that mismatch neurons that receive motorrelated input also receive matched bottom-up inhibitory input from a specific subset of somatostatin (SST)-positive interneurons (Attinger et al., 2017). Thus, EGR1 expression may be preferentially increased in neurons that are driven by excitatory top-down input and SST mediated bottom-up inhibition, while Arc expression may be preferentially increased in neurons that are driven by excitatory 
252

bottom-up visual input. This may explain why a change to the visual input alone at first visual exposure primarily resulted in a rearrangement of the Arc expression pattern (Figure 2D), but left the EGR1 expression pattern relatively unaffected (Figure 2F), while first exposure to normal visuomotor coupling resulted in a rearrangement of the expression pattern of both Arc and EGR1.

When interpreting our results, it should be kept in mind that both the method we use to approximate IEG expression levels and the method we use to approximate neuronal activity levels come with a series of caveats. In the case of the transgenic mice used for the IEG expression measurements, two of these express a fusion protein (Arc and c-Fos), where the IEG is likely overexpressed (Steward et al., 2017), and it is possible that the decay kinetics of the fusion protein differ from those of the native protein. In the case of the GFP driven by the egr1 promoter, the GFP decay kinetics are likely different from the decay kinetics of EGR1. However, these potential differences in decay kinetics and expression levels do not completely mask the correlation between IEG expression levels and reporter proteins. In post-mortem histological stainings the expression of GFP in these mouse lines overlaps well with the expression levels of the IEGs (Barth et al., 2004; Okuno et al., 2012; Xie et al., 2014; Yassin et al., 2010). Thus, reporter protein levels reflect a filtered version of IEG expression levels, and the two are likely related by a monotonic function. Given that all our analyses rely only on relative expression levels among populations of simultaneously recorded neurons or relative changes of expression levels in time, the lack of a direct measurement of IEG expression levels should not change our conclusions. A second caveat concerns the genetically encoded calcium indicator used to measure neuronal activity. Our activity measures are biased towards bursts of neuronal activity, as single spikes are probably not always detectable using calcium indicators in vivo. However, even though the transfer function from neuronal activity to calcium signal is non-linear, it is also monotonic. Thus, we may be underestimating the correlation between neuronal activity and IEG expression, but neither caveat would bias the results towards finding specific correlations between different IEGs and functional cell types.

In summary, our results suggest that the expression of Arc and EGR1 in layer 2/3 neurons in mouse visual cortex may be a correlate of the type of functional input the neuron receives. Such a preference for expression in a functionally specific subset of neurons would be consistent with differential changes in the ratio of the expression of different IEGs under conditions that result in identical mean levels of neuronal activity (Bailey and Wade, 2003; Farina and Commins, 2016; Guzowski et al., 2006) that are difficult to explain if IEG expression were simply driven by mean activity. In future experiments, it will be 
bioRxiv preprint doi: https://doi.org/10.1101/2020.11.12.379909; this version posted November 12, 2020. The copyright holder for this preprint (which was not certified by peer review) is the author/funder, who has granted bioRxiv a license to display the preprint in perpetuity. It is made available under aCC-BY-NC 4.0 International license.

282 important to establish a more detailed picture of how immediate early genes could orchestrate or 283 stabilize the pattern of functionally distinct input streams a neuron receives. 
bioRxiv preprint doi: https://doi.org/10.1101/2020.11.12.379909; this version posted November 12, 2020. The copyright holder for this preprint (which was not certified by peer review) is the author/funder, who has granted bioRxiv a license to display the preprint in perpetuity. It is made available under aCC-BY-NC 4.0 International license.

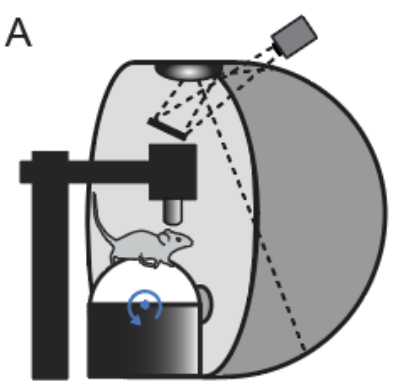

B

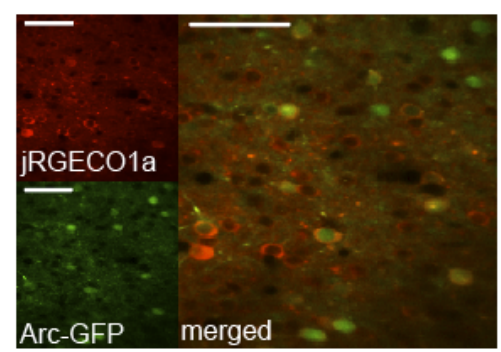

$\mathrm{E}$

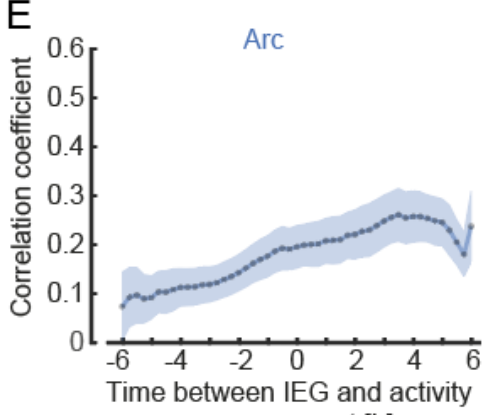

measurement [h]

$\mathrm{H}$

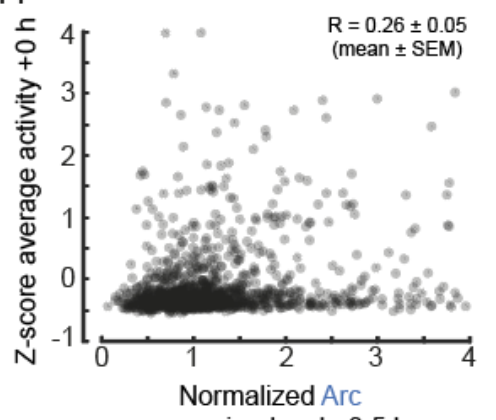

expression level $+3.5 \mathrm{~h}$

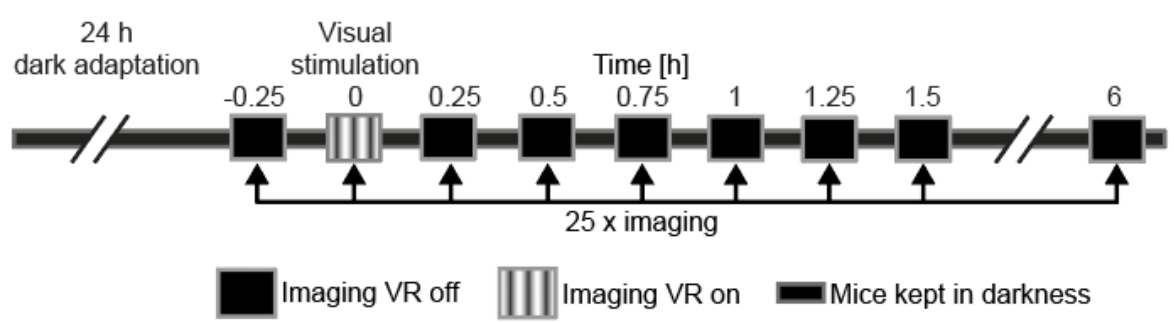

C

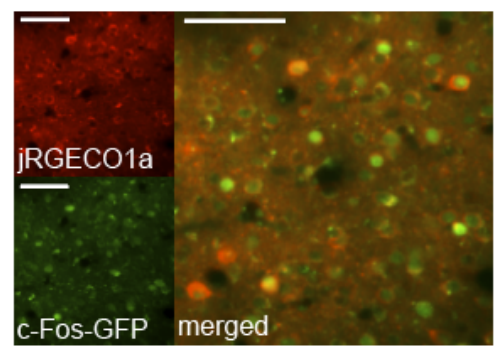

$\mathrm{F}$

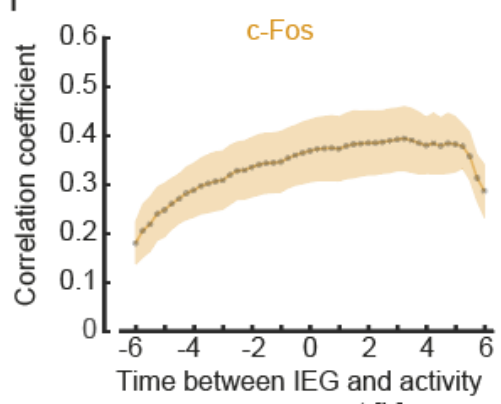

measurement [h]

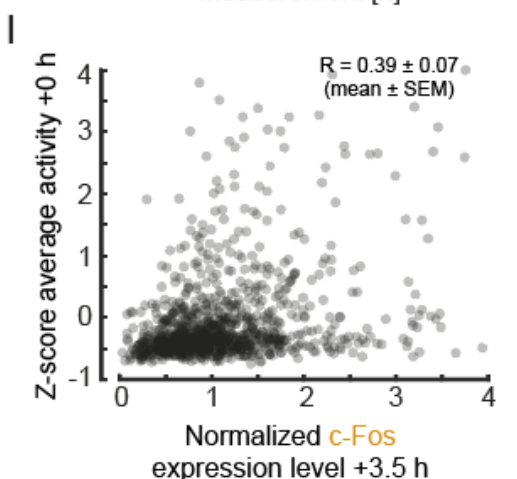

D

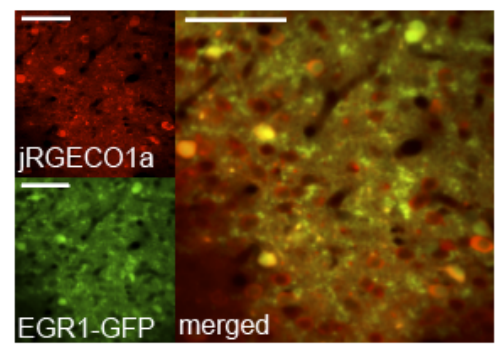

G

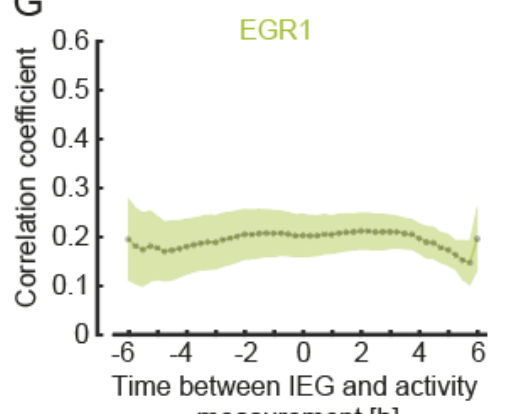

measurement $[\mathrm{h}]$

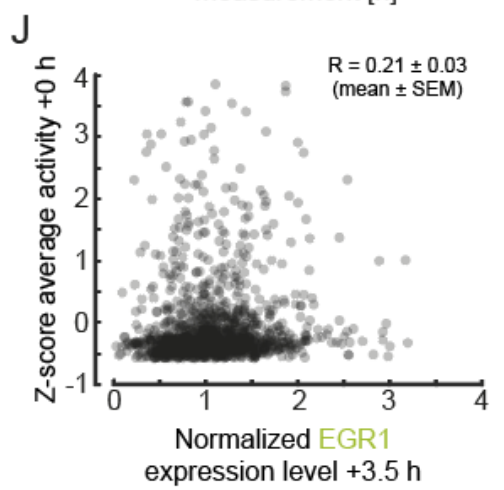


289 (A) Left: Schematic of the virtual reality setup used for imaging experiments. Right: Schematic of the 290 experimental timeline. Mice were dark-adapted for 24 hours. Neuronal activity and IEG expression levels 291 were recorded in 25 imaging sessions starting immediately before and continuing until 6 hours after 292 visual stimulation in intervals of 15 minutes.

293 (B) Example two-photon images of neurons in primary visual cortex labelled with jRGECO1a (red, top 294 left), Arc (green, bottom left), and the overlay (right). Scale bar is $50 \mu \mathrm{m}$.

295 (C) Same as in (B), but for c-Fos.

296 (D) Same as in (B), but for EGR1.

297 (E) Correlation of average activity and IEG expression level as a function of the time difference between 298 the two measurements. Dotted line indicates average correlation, shading indicates standard error of 299 the mean (SEM) across mice $(n=4)$.

300 (F) Same as in (E), but for c-Fos mice $(n=4)$.

301 (G) Same as in (E), but for EGR1 mice $(n=4)$.

302 (H) Scatter plot of Arc expression 3.5 hours after visual stimulation and average neuronal activity during 303 visual stimulation (1382 neurons in 4 mice, 83 neurons outside of plot range). Shown in the panel is the 304 average correlation coefficient across mice (mean $\pm S E M, n=4)$.

305 (I) Same as in (H), but for c-Fos (1070 neurons in 4 mice, 28 neurons outside of plot range).

306 (J) Same as (H), but for EGR1 (1319 neurons in 4 mice, 18 neurons outside of plot range). 
A



B

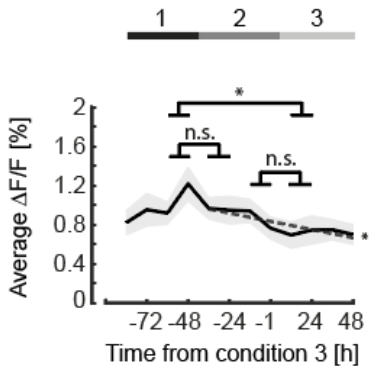

C Condition

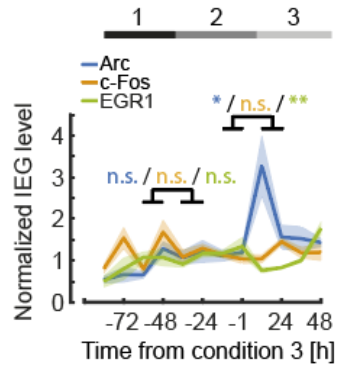

$\mathrm{D}$

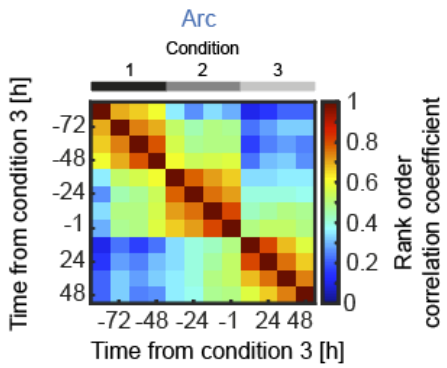

$\mathrm{E}$



$\mathrm{F}$



Figure 2. IEG expression dynamics during visuomotor learning.

312 (A) Schematic of the experimental timeline. Mice were born and reared in complete darkness. jRGECO1a was injected 10 to 12 days prior to the start of imaging experiments. We then imaged calcium activity and IEG expression levels every $12 \mathrm{~h}$ over the course of 6 days both before and after first visual exposure and first exposure to normal visuomotor coupling. On the first two days (condition 1 ) activity in visual cortex was recorded in complete darkness while mice were head-fixed and free to run on a spherical treadmill. On the third day of recording mice were exposed to visual feedback (first visual exposure) in a virtual reality environment. Outside of the recording sessions mice were still housed in complete darkness (condition 2). Starting on day 5, mice were subjected to a $12 \mathrm{~h} / 12 \mathrm{~h}$ light/dark cycle (condition 3).

(B) Average calcium activity during all conditions (condition 1 vs. 2: $p=0.2183$, condition 2 vs. $3: p=$ 0.527 , condition 1 vs. 3: $p=0.0123,5067$ neurons, paired t-test). Shading is SEM over mice. Dashed line indicates linear fit to the data of conditions 2 and 3 . The linear fit to the data from conditions 2 and 3 exhibited a significant negative slope $\left(p=0.0293, R^{2}=0.371\right.$, linear trend analysis, see Methods).

(C) Normalized mean IEG expression levels during all conditions. Expression level of Arc (blue, 1969 neurons in 7 mice) significantly increased after first exposure to visuomotor coupling, decreased for EGR1 (green, 1213 neurons in 4 mice) and remained unchanged for c-Fos (orange, 1885 neurons in 5 mice). Change in IEG expression level between conditions 1 and 2 for Arc: $0.1764 \pm 0.1556, p=0.2775$; cFos: $-0.0536 \pm 0.1877, p=0.7816$; EGR1: $-0.0371 \pm 0.1246, p=0.7745$ (mean $\pm S E M$, paired t-test). Change in IEG expression level between conditions 2 and 3 for Arc: $1.2628 \pm 0.5012, p=0.0256$; c-Fos: $0.01612 \pm 0.1372, p=0.2702 ; E G R 1:-0.4568 \pm 0.1130, p=0.0049$ (mean $\pm S E M, t$-test). Shading

332 indicates SEM over mice. 
bioRxiv preprint doi: https://doi.org/10.1101/2020.11.12.379909; this version posted November 12, 2020. The copyright holder for this preprint (which was not certified by peer review) is the author/funder, who has granted bioRxiv a license to display the preprint in perpetuity. It is made available under aCC-BY-NC 4.0 International license.

333 (D) Average rank order correlation coefficients for Arc expression during visuomotor learning (7 mice). 334 The expression pattern changes both at the onset of conditions 2 and 3.

335 (E) Same as in (D), but for c-Fos (5 mice). The expression pattern exhibits no apparent transitions.

336 (F) Same as in (D), but for EGR1 (4 mice). The expression pattern changes at the onset of condition 3. 
A

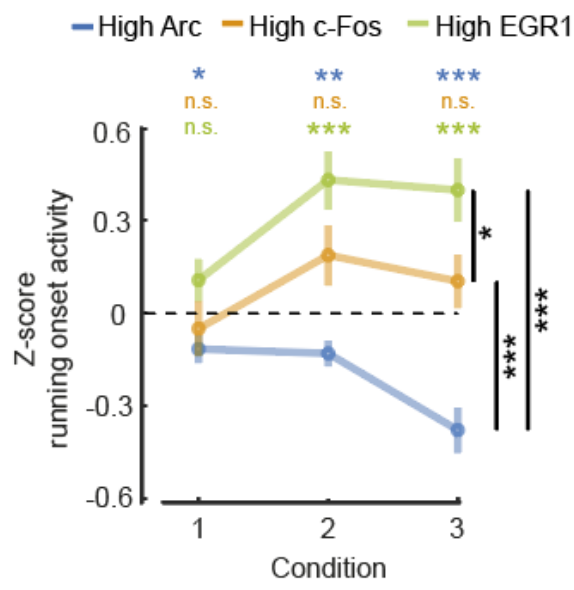

B

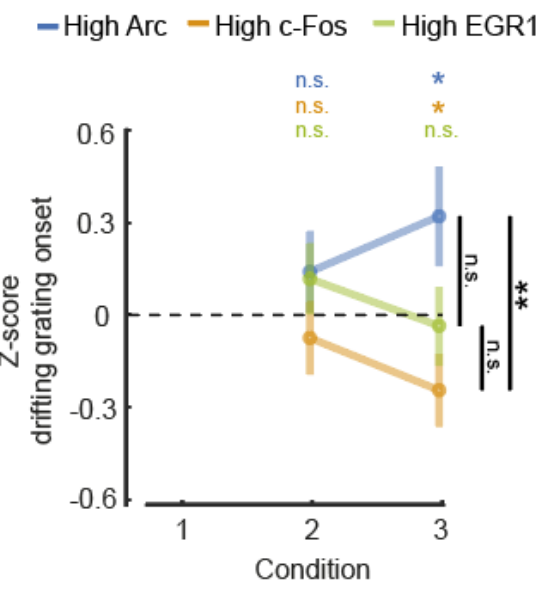

Figure 3. Differential relationship between IEG expression and motor-related and visual responses.

340 (A) Average running onset response during darkness for the top $10 \%$ IEG expressing neurons (Arc: 197

341 neurons, c-Fos: 189 neurons, EGR1: 121 neurons). Neuronal responses were pooled from all

342 experimental sessions for each condition, subtracted by the mean and normalized by the standard

343 deviation of the response of all neurons (Z-score). Error bars are SEM over neurons. Statistics above the

344 plot indicate comparisons against 0 , statistics to the right are between-group comparisons. n.s.: $p>0.05$,

$345 *$ : $p<0.05, * *: p<0.01, * * * p<0.001$, t-test.

346 (B) Average grating onset response for the top $10 \%$ IEG expressing neurons (Arc: $n=197, c-F o s: n=189$,

347 EGR1: $n=121)$. Neuronal responses were pooled from all experimental sessions for conditions 2 and 3,

348 subtracted by the mean and normalized by standard deviation of the response of all neurons (Z-score).

349 Error bars are SEM over neurons. Statistics above the plot indicate comparisons against 0 , statistics to

350 the right are between-group comparisons. n.s.: $p>0.05, *$ : $<0.05, * *$ : $p<0.01, * * * p<0.001$, t-test. 

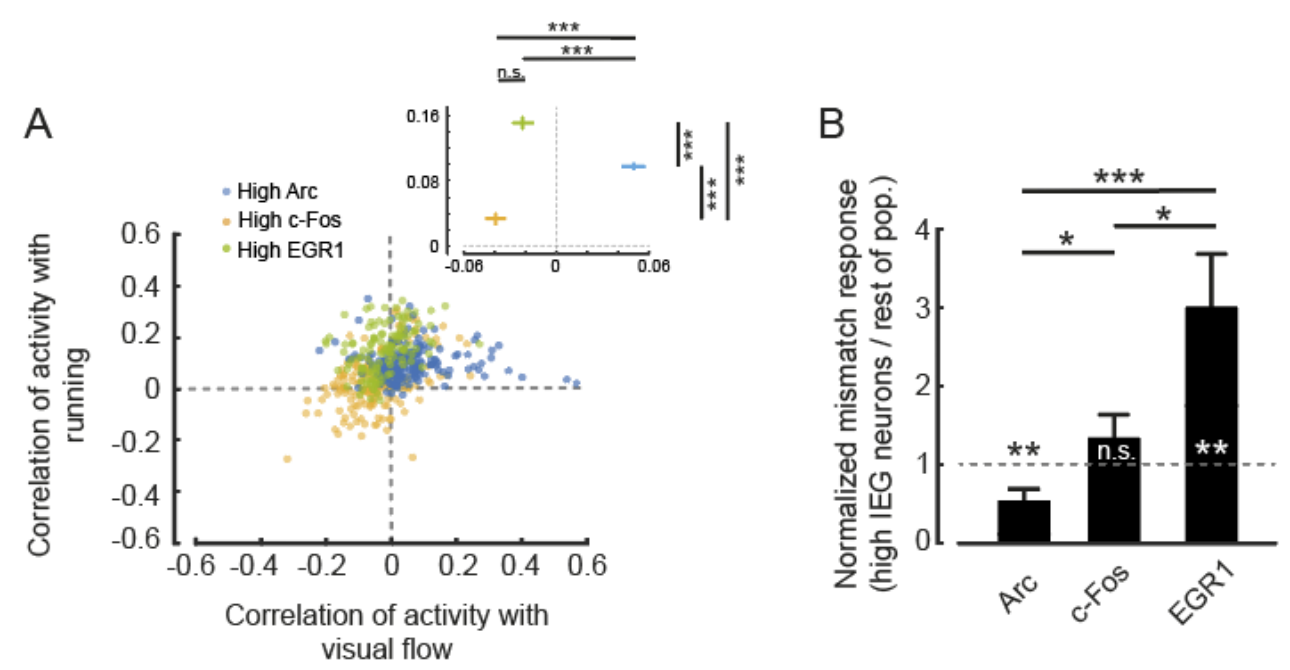

354 Figure 4. Functional cell type specific expression of IEGs in visual cortex.

355 (A) Correlation of neuronal activity with running and of neuronal activity with visual flow during openloop phases of conditions 2 and 3 for the top 10 \% IEG expressing neurons (Arc: 197 neurons, c-Fos: 189 neurons, EGR1: 121 neurons). Inset: Average correlation coefficient for the three groups of high IEG expressing neurons. High Arc expressing neurons had the highest correlation with visual flow (Arc vs. cFos: $p<10^{-10}$, Arc vs. EGR1: $p<10^{-9}$, c-Fos vs. EGR1: $p=0.0791$, t-test), while high EGR1 expressing neurons had the highest correlation with running (Arc vs. c-Fos: $p<10^{-10}$, Arc vs. EGR1: $p<10^{-8}$, c-Fos vs. EGR1: $p<10^{-10}$, t-test).

(B) Mismatch responses in condition 3 were significantly higher for the top $10 \%$ EGR1 expressing neurons and significantly lower for the top $10 \%$ Arc expressing neurons than the rest of the respective population (Arc: 197 neurons, c-Fos: 189 neurons, EGR1: 121 neurons). Arc: $p=0.0461$, c-Fos: $p=$ 0.2273, EGR1: $p=0.0234$; Arc vs. c-Fos: $p=0.0101$, c-Fos vs. EGR1: $p=0.048$, Arc vs. EGR1: $p=0.0057, t-$ test. 
370
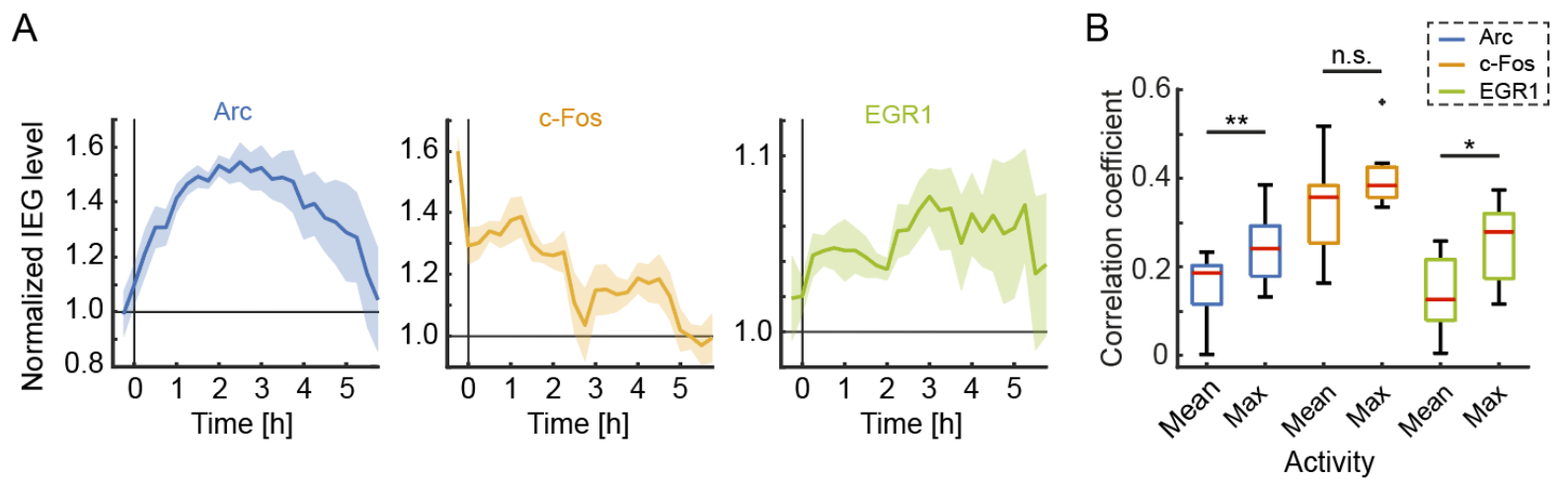

371

372

Figure S1. Time course of IEG expression during the imaging paradigm and correlation of IEG

373 expression with mean and maximum neuronal activity. Related to Figure 1.

374 (A) Time course of normalized IEG expression levels following $24 \mathrm{~h}$ dark adaptation and 15 min visual

375 stimulation at time 0 . Shading indicates SEM over neurons.

376 (B) Correlation coefficient of mean and maximum activity (average across or peak within a recording

377 session, respectively) with IEG expression $3.5 \mathrm{~h}$ after stimulation or recording onset (Arc: 11 mice, c-Fos:

378 9 mice, EGR1: 8 mice). Box whisker plot: red line indicates median, box marks 25th to 75th percentiles

379 and whiskers extended to the next most extreme datapoint within a range of 1.5 times the interquartile distance (rank sum test, Arc: $p=0.0086, c-F o s: p=0.1359, E G R 1: p=0.0207$ ). 
bioRxiv preprint doi: https://doi.org/10.1101/2020.11.12.379909; this version posted November 12,2020 . The copyright holder for this preprint (which was not certified by peer review) is the author/funder, who has granted bioRxiv a license to display the preprint in perpetuity. It is made available under aCC-BY-NC 4.0 International license.

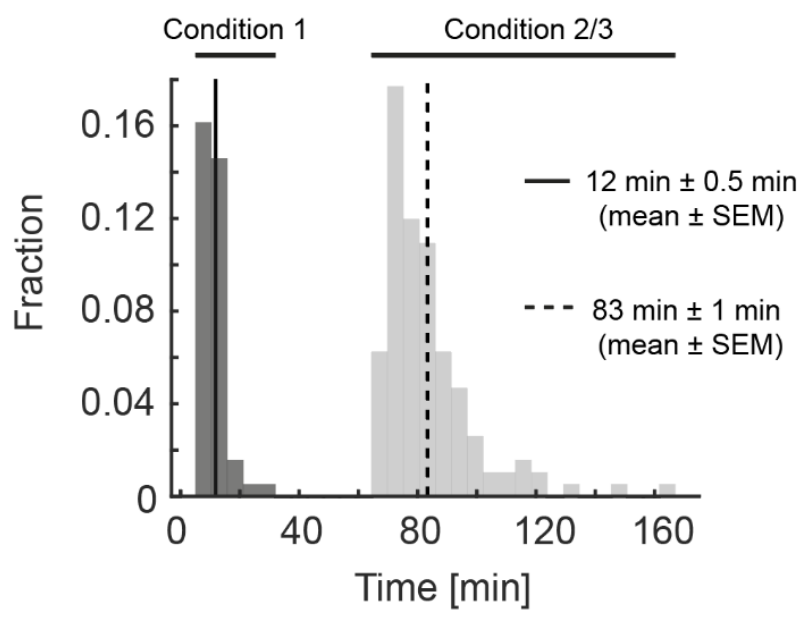

383 Figure S2. Duration of recording sessions. Related to Figure 2.

384 Histogram of the durations of the recording sessions. On average, one recording session lasted for

385 approximately 12 min during condition 1 (solid line) and, due to the addition of closed-loop, open-loop, 386 and grating stimulation phases, 83 min during conditions 2 and 3 (dashed line). 


\section{METHODS}

Animals and surgery. All animal procedures were approved by and carried out in accordance with guidelines of the Veterinary Department of the Canton Basel-Stadt, Switzerland. We used imaging data from a total of 11 EGFP-Arc mice (Okuno et al., 2012), 9 c-Fos-GFP mice (Barth et al., 2004) and 8 EGR1GFP mice (Xie et al., 2014), aged 40 days at the start of visuomotor learning (Figures 2 - 4) or aged 100104 (Arc), 279-291 (c-Fos) or 120-124 (EGR1) days (Figure 1). Sample sizes were chosen according to the standards in the field and no statistical methods were used to predetermine sample sizes. Mice were group-housed in a dark cabinet and in a vivarium (light/dark cycle: $12 \mathrm{~h} / 12 \mathrm{~h}$ ). Viral injections and window implantation were performed as previously described (Dombeck et al., 2010; Leinweber et al., 2014). Briefly, for sensorimotor learning experiments, mice (aged $29 \mathrm{~d} \pm 1 \mathrm{~d}$, mean \pm SEM) were anesthetized in darkness using a mix of fentanyl $(0.05 \mathrm{mg} / \mathrm{kg})$, medetomidine $(0.5 \mathrm{mg} / \mathrm{kg})$ and midazolam ( $5 \mathrm{mg} / \mathrm{kg}$ ), and additionally their eyes were covered with a thick, black cotton fabric during all surgical procedures. A $3 \mathrm{~mm}$ to $5 \mathrm{~mm}$ craniotomy was made above visual cortex $(2.5 \mathrm{~mm}$ lateral of lambda (Paxinos and Franklin, 2013)) and AAV2/1-Ef1a-NES-jRGECO1a-WPRE ((Dana et al., 2016); titer: between $7.2 \times 10^{10} \mathrm{GC} / \mathrm{ml}$ and $6.8 \times 10^{12} \mathrm{GC} / \mathrm{ml}$ ) was injected into the target region. The craniotomy was sealed with a fitting cover slip. A titanium head bar was attached to the skull and stabilized with dental cement.

Imaging and virtual reality. Imaging commenced 10-12 (visuomotor learning experiments, Figures 2 4) or 12-29 (Figure 1) days following virus injection and was carried out using a custom-built twophoton microscope. Illumination source was a Chameleon Vision laser (Coherent) tuned to a wavelength of either $950 \mathrm{~nm}, 990 \mathrm{~nm}$ or $1030 \mathrm{~nm}$. Imaging was performed using an $8 \mathrm{kHz}$ resonance scanner (Cambridge Technology) resulting in frame rates of $40 \mathrm{~Hz}$ at a resolution of $400 \times 750$ pixels. In addition, we used a piezo actuator (Physik Instrumente) to move the objective (Nikon 16x, 0.8 NA) in steps of 15 $\mu \mathrm{m}$ between frames to acquire images at four different depths, thus reducing the effective frame rate to $10 \mathrm{~Hz}$. The behavioral imaging setup was as previously described (Leinweber et al., 2014). After brief isoflurane anesthesia mice were head-fixed in complete darkness and the setup was light-shielded before every imaging session. Mice were free to run on an air-supported polystyrene ball, the motion of which was restricted to the forward and backward directions by a pin. The ball's rotation was coupled to linear displacement in the virtual environment that was projected onto a toroidal screen surrounding the mouse. The screen covered a visual field of approximately 240 degrees horizontally and 100 degrees vertically. All displayed elements of the tunnel or sinusoidal gratings were calibrated to be isoluminant. 
Experimental design. For experiments shown in Figure 1, mice were dark-adapted for $24 \mathrm{~h}$ and $17 \mathrm{~min} \pm$ 10 min (mean \pm SEM, 12 mice) before head fixation under the microscope in darkness. Activity and

421 immediate early gene expression were recorded every 15 minutes for 6 hours. Except for the time of

422 visual stimulation with sinusoidal gratings moving in 8 different directions (a total of 80 presentation in

423 random order), mice were kept in complete darkness under the microscope for the duration of the

424 entire experiment. For visuomotor learning experiments (Figures 2 - 4) mice were born and reared in complete darkness until P44 and then transferred to a vivarium with a $12 \mathrm{~h} / 12 \mathrm{~h}$ light/dark cycle. Experimental sessions started on P40 and occurred twice per day, spaced $12 \mathrm{~h}$ apart. In condition 1 , all imaging was done in complete darkness and experiments consisted of recording approximately 8 min of neuronal activity during which mice were free to run on the spherical treadmill. IEG expression level measurements were taken before and after each activity recording. In conditions 2 and 3, neuronal activity measurements consisted of 7 recordings of approximately 8 minutes each. Each recording session started with a recording in darkness, followed by a closed-loop recording. In the closed-loop recording, the movement of the mouse in a linear virtual corridor (sinusoidal vertical grating) was coupled to the locomotion of the mouse on the spherical treadmill. During the closed-loop session we included brief (1 s) halts of visual flow to induce mismatch events (Attinger et al., 2017). The subsequent two recordings were of the open-loop type and consisted of a playback of the visual flow the mouse had generated during the preceding closed-loop recording. Subsequently, mice were exposed to a second recording in darkness, followed by a visual stimulation recording. During the visual stimulation sinusoidal moving grating stimuli ( 2 second standing grating, 3 second drifting grating, 8 different orientations, 10 presentations of each orientation, in a randomized order) were presented. Finally, mice were exposed to a third recording in darkness. In early phases of the experiment mice were encouraged

441 to run by applying occasional mild air puffs to the neck.

442 Data analysis. Imaging data were full-frame registered using a custom-written software (Leinweber et

443 al., 2014). Neurons were selected manually based on their mean fluorescence or maximum projection in 444 the red channel (jRGECO1a). This biased our selection towards active neurons. Fluorescence traces were 445 calculated as the mean pixel value in each region of interest per frame, and were then median446 normalized to calculate $\Delta F / F . \Delta F / F$ traces were filtered as previously described (Dombeck et al., 2007). 447 GFP intensities were calculated as the mean pixel value in each region of interest (ROI) for mean 448 fluorescence projections. To compensate for expression level differences between different IEG mouse 449 lines as well as for image quality differences between different mice we normalized the GFP level 
measurements as follows: For each mouse, all ROI measurements were subtracted by the minimum calculated over all ROIs and timepoints, and normalized by the median over all ROIs and timepoints.

$$
R O I_{\text {normalized }}^{i, t p}=\left(R O I^{i, t p}-\min _{i, t p} R O I^{i, t p}\right) /\left(\operatorname{median}_{i, t p} R O I^{i, t p}-\min _{i, t p} R O I^{i . t p}\right)
$$

This ensured that the minimum value of IEG expression was 0 and the median 1 . No blinding of experimental condition was performed in any of the analyses. Statistical tests were used as stated in the figure legends.

456 Figure 1. Examples images (Figures 1B-1D) are average projections of the recorded channel. IEG expression was normalized as described above (Figures 1E-1G). Correlation coefficients (Figures 1E-1G) were calculated based on the neuronal population vectors of average activity and IEG expression per measurement timepoint, for each mouse. For the statistical comparison of the correlation coefficients of

460 IEG expression levels with neural activity between the three different groups (4 mice per group), data 461 were bootstrapped 5 times with random replacement and then a t-test was performed on the 462 bootstrapped data.

463 Figure 2. To compare changes in neural activity and IEG expression levels between conditions we 464 averaged data from the last two recording sessions of the previous condition and the first two recording sessions of the following condition (Figures 2B and 2C). Linear trend analysis (Figure 2B) was performed

466 using the MATLAB regress function. To quantify the significance of the linear trend we report the $\mathrm{R}^{2}$

467 statistic and p-value of the F statistic. Linear fits were performed for each mouse individually using the

468 MATLAB polyfit and polyval functions. Rank order correlation coefficients (Figures 2D-2F) were

469 determined based on the population vectors of average IEG expression per measurement timepoint and 470 mouse, and then averaged.

471 Figure 3. For plots of event-triggered activity changes $\Delta \mathrm{F} / \mathrm{F}$ traces were baseline-subtracted by the 472 average $\Delta \mathrm{F} / \mathrm{F}$ in a window $-500 \mathrm{~ms}$ to -100 ms preceding the event onset. Z-scores were obtained on a 473 population vector with average stimulus onset values calculated over a response window of $1.5 \mathrm{~s}$. High 474 IEGs neurons were selected as the top $10 \%$ of IEG expressing neurons based on average expression level 475 on the first day of condition 3.

476 Figure 4. Correlation coefficients (Figure 4A) were calculated by correlating each neuron's activity trace 477 with either the running trace or the visual flow trace during open-loop phases. High IEG neurons were 478 selected with the same criteria used for Figure 3. Stimulus-triggered fluorescence changes (Figure 4B) 
479 were mean-subtracted in a window $-500 \mathrm{~ms}$ to $-100 \mathrm{~ms}$ preceding the stimulus onset. Responses were 480 quantified in a window of $1.5 \mathrm{~s}$.

481 Figure S1. Correlation coefficients of mean or maximum activity with IEG expression were calculated for

482 each mouse (Figure S1B). Mice from visual stimulation experiments (Figure 1) and sensorimotor learning

483 experiments (Figures 2-4) were pooled for this analysis. For mice from the sensorimotor learning

484 experiments the calculation was done using mean or maximum activity of the first recording segment

485 and the last IEG measurement within a session. Shown is the average correlation across all sessions.

486 Code and data availability. All imaging and image processing code can be found online at

487 https://sourceforge.net/projects/iris-scanning/ (IRIS, imaging software package) and

488 https://sourceforge.net/p/iris-scanning/calliope/HEAD/tree (Calliope, image processing software

489 package). All the raw data and analysis code used in this study can be downloaded from the following

490 website: http://data.fmi.ch/PublicationSupplementRepo/.

\section{ACKNOWLEDGEMENTS}

493 We thank the entire Keller lab for helpful discussion and comments on earlier versions of this

494 manuscript. We thank Daniela Gerosa-Erni for production of the AAV vectors. This work was supported

495 by the Swiss National Science Foundation (GBK), the Novartis Research Foundation (GBK), the Human

496 Frontier Science Program (GBK), and JSPS-Kakenhi and AMED (HO and HB).

\section{AUTHOR CONTRIBUTIONS}

499 D.M. and P.Z. performed the experiments, D.M. analyzed the data. H.O. and H.B. made the EGFP-ArC mouse. All authors wrote the manuscript. 


\section{REFERENCES}

502 Attinger, A., Wang, B., and Keller, G.B. (2017). Visuomotor Coupling Shapes the Functional Development 503 of Mouse Visual Cortex. Cell 169, 1291-1302.e14.

504 Bailey, D.J., and Wade, J. (2003). Differential expression of the immediate early genes FOS and ZENK 505 following auditory stimulation in the juvenile male and female zebra finch. Brain Res. Mol. Brain Res. $506116,147-154$.

507 Barth, A.L., Gerkin, R.C., and Dean, K.L. (2004). Alteration of Neuronal Firing Properties after In Vivo 508 Experience in a FosGFP Transgenic Mouse. J. Neurosci. 24, 6466-6475.

509 Bozon, B., Kelly, A., Josselyn, S.A., Silva, A.J., Davis, S., and Laroche, S. (2003). MAPK, CREB and zif268 are 510 all required for the consolidation of recognition memory. Philos. Trans. R. Soc. Lond. B. Biol. Sci. 358, $511805-814$.

512 Bullitt, E. (1990). Expression of C-fos-like protein as a marker for neuronal activity following noxious 513 stimulation in the rat. J. Comp. Neurol. 296, 517-530.

514 Chang, M.C., Park, J.M., Pelkey, K.A., Grabenstatter, H.L., Xu, D., Linden, D.J., Sutula, T.P., McBain, C.J., 515 and Worley, P.F. (2010). Narp regulates homeostatic scaling of excitatory synapses on parvalbumin516 expressing interneurons. Nat Neurosci 13, 1090-1097.

517 Chowdhury, S., Shepherd, J.D., Okuno, H., Lyford, G., Petralia, R.S., Plath, N., Kuhl, D., Huganir, R.L., and 518 Worley, P.F. (2006). Arc/Arg3.1 Interacts with the Endocytic Machinery to Regulate AMPA Receptor 519 Trafficking. Neuron 52, 445-459.

520 Dana, H., Mohar, B., Sun, Y., Narayan, S., Gordus, A., Hasseman, J.P., Tsegaye, G., Holt, G.T., Hu, A., 521 Walpita, D., et al. (2016). Sensitive red protein calcium indicators for imaging neural activity. Elife 5.

522 Denny, C.A., Kheirbek, M.A., Alba, E.L., Tanaka, K.F., Brachman, R.A., Laughman, K.B., Tomm, N.K., Turi, 523 G.F., Losonczy, A., and Hen, R. (2014). Hippocampal Memory Traces Are Differentially Modulated by 524 Experience, Time, and Adult Neurogenesis. Neuron 83, 189-201.

525 Dombeck, D.A., Khabbaz, A.N., Collman, F., Adelman, T.L., and Tank, D.W. (2007). Imaging Large-Scale 526 Neural Activity with Cellular Resolution in Awake, Mobile Mice. Neuron 56, 43-57.

527 Dombeck, D.A., Harvey, C.D., Tian, L., Looger, L.L., and Tank, D.W. (2010). Functional imaging of 528 hippocampal place cells at cellular resolution during virtual navigation. Nat. Neurosci. 13, 1433-1440. 
Dudek, S. (2008). Transcriptional Regulation by Neuronal Activity (Boston, MA: Springer US).

530

531

532

533

534

535

536

537

538

539

540

541

542

543

544

545

546

547

548

549

550

551

552

553

554

555

556

Farina, F.R., and Commins, S. (2016). Differential expression of immediate early genes Zif268 and c-Fos

in the hippocampus and prefrontal cortex following spatial learning and glutamate receptor antagonism.

Behav. Brain Res. 307, 194-198.

Fleischmann, A., Hvalby, O., Jensen, V., Strekalova, T., Zacher, C., Layer, L.E., Kvello, A., Reschke, M., Spanagel, R., Sprengel, R., et al. (2003). Impaired Long-Term Memory and NR2A-Type NMDA ReceptorDependent Synaptic Plasticity in Mice Lacking c-Fos in the CNS. J. Neurosci. 23, 9116-9122.

Gandolfi, D., Cerri, S., Mapelli, J., Polimeni, M., Tritto, S., Fuzzati-Armentero, M.-T., Bigiani, A., Blandini, F., Mapelli, L., and D'Angelo, E. (2017). Activation of the CREB/c-FosPathway during Long-Term Synaptic Plasticity in the Cerebellum Granular Layer. Front. Cell. Neurosci. 11, 184.

Gao, M., Sossa, K., Song, L., Errington, L., Cummings, L., Hwang, H., Kuhl, D., Worley, P., and Lee, H.-K. (2010). A Specific Requirement of Arc/Arg3.1 for Visual Experience-Induced Homeostatic Synaptic Plasticity in Mouse Primary Visual Cortex. J. Neurosci. 30, 7168-7178.

Garner, A.R., Rowland, D.C., Hwang, S.Y., Baumgaertel, K., Roth, B.L., Kentros, C., and Mayford, M. (2012). Generation of a Synthetic Memory Trace. Science 335, 1513-1516.

Greenberg, M.E., and Ziff, E.B. (1984). Stimulation of 3 T3 cells induces transcription of the c-fos protooncogene. Nature 311, 433-438.

Gu, Y., Huang, S., Chang, M.C., Worley, P., Kirkwood, A., and Quinlan, E.M. (2013). Obligatory Role for the Immediate Early Gene NARP in Critical Period Plasticity. Neuron 79, 335-346.

Guzowski, J.F. (2002). Insights into immediate-early gene function in hippocampal memory consolidation using antisense oligonucleotide and fluorescent imaging approaches. Hippocampus 12, 86-104.

Guzowski, J.F., and McGaugh, J.L. (1997). Antisense oligodeoxynucleotide-mediated disruption of hippocampal cAMP response element binding protein levels impairs consolidation of memory for water maze training. Proc. Natl. Acad. Sci. U. S. A. 94, 2693-2698.

Guzowski, J.F., McNaughton, B.L., Barnes, C.A., and Worley, P.F. (1999). Environment-specific expression of the immediate-early gene Arc in hippocampal neuronal ensembles. Nat. Neurosci. 2, 1120-1124.

Guzowski, J.F., Lyford, G.L., Stevenson, G.D., Houston, F.P., McGaugh, J.L., Worley, P.F., and Barnes, C. a (2000). Inhibition of activity-dependent arc protein expression in the rat hippocampus impairs the 
maintenance of long-term potentiation and the consolidation of long-term memory. J. Neurosci. 20, 3993-4001.

Guzowski, J.F., Miyashita, T., Chawla, M.K., Sanderson, J., Maes, L.I., Houston, F.P., Lipa, P., McNaughton, B.L., Worley, P.F., and Barnes, C.A. (2006). Recent behavioral history modifies coupling between cell activity and Arc gene transcription in hippocampal CA1 neurons. Proc. Natl. Acad. Sci. United States Am. $103,1077-1082$.

Holtmaat, A., and Caroni, P. (2016). Functional and structural underpinnings of neuronal assembly formation in learning. Nat. Neurosci. 19, 1553-1562.

Jarvis, E.D., Ribeiro, S., Da Silva, M.L., Ventura, D., Vielliard, J., and Mello, C. V. (2000). Behaviourally driven gene expression reveals song nuclei in hummingbird brain. Nature 406, 628-632.

Jenks, K.R., Kim, T., Pastuzyn, E.D., Okuno, H., Taibi, A. V, Bito, H., Bear, M.F., and Shepherd, J.D. (2017). Arc restores juvenile plasticity in adult mouse visual cortex. Proc. Natl. Acad. Sci. 114, 9182-9187.

Jones, M.W., Errington, M.L., French, P.J., Fine, A., Bliss, T.V.P., Garel, S., Charnay, P., Bozon, B., Laroche, S., and Davis, S. (2001). A requirement for the immediate early gene Zif268 in the expression of late LTP and long-term memories. Nat. Neurosci. 4, 289-296.

Josselyn, S.A., Köhler, S., and Frankland, P.W. (2015). Finding the engram. Nat. Rev. Neurosci. 16, 521534.

Kaminska, B., Kaczmarek, L., and Chaudhuri, A. (1996). Visual Stimulation Regulates the Expression of Transcription Factors and Modulates the Composition of AP-1 in Visual Cortexa. J. Neurosci. 16, 39683978.

Kaplan, I. V, Guo, Y., and Mower, G.D. (1996). Immediate early gene expression in cat visual cortex during and after the critical period: differences between EGR-1 and Fos proteins. Brain Res. Mol. Brain Res. 36, 12-22.

Kawashima, T., Kitamura, K., Suzuki, K., Nonaka, M., Kamijo, S., Takemoto-Kimura, S., Kano, M., Okuno, H., Ohki, K., and Bito, H. (2013). Functional labeling of neurons and their projections using the synthetic activity-dependent promoter E-SARE. Nat. Methods 10, 889-895.

Keck, T., Keller, G.B., Jacobsen, R.I., Eysel, U.T., Bonhoeffer, T., and Hübener, M. (2013). Synaptic scaling and homeostatic plasticity in the mouse visual cortex in vivo. Neuron 80. 
Keller, G.B., and Mrsic-Flogel, T.D. (2018). Predictive Processing: A Canonical Cortical Computation. Neuron 100, 424-435.

Keller, G.B., Bonhoeffer, T., and Hübener, M. (2012). Sensorimotor mismatch signals in primary visual cortex of the behaving mouse. Neuron 74, 809-815.

Knapska, E., and Kaczmarek, L. (2004). A gene for neuronal plasticity in the mammalian brain: Zif268/Egr-1/NGFI-A/Krox-24/TIS8/ZENK? Prog. Neurobiol. 74, 183-211.

Leinweber, M., Zmarz, P., Buchmann, P., Argast, P., Hübener, M., Bonhoeffer, T., and Keller, G.B. (2014). Two-photon calcium imaging in mice navigating a virtual reality environment. J. Vis. Exp. e50885.

Leinweber, M., Ward, D.R., Sobczak, J.M., Attinger, A., and Keller, G.B. (2017). A Sensorimotor Circuit in Mouse Cortex for Visual Flow Predictions. Neuron 95, 1420-1432.e5.

Liu, X., Ramirez, S., Pang, P.T., Puryear, C.B., Govindarajan, A., Deisseroth, K., and Tonegawa, S. (2012). Optogenetic stimulation of a hippocampal engram activates fear memory recall. Nature 484, 381-385.

Mahringer, D., Petersen, A., Fiser, A., Okuno, H., Bito, H., Perrier, J.-F., and Keller, G. (2019). Expression of c-Fos and Arc in hippocampal region CA1 marks neurons that exhibit learning-related activity changes. BioRxiv 644526.

Makino, H., and Komiyama, T. (2015). Learning enhances the relative impact of top-down processing in the visual cortex. Nat. Neurosci. 18, 1116-1122.

Mataga, N., Fujishima, S., Condie, B.G., and Hensch, T.K. (2001). Experience-Dependent Plasticity of Mouse Visual Cortex in the Absence of the Neuronal Activity-Dependent Markeregr1/zif268 . J. Neurosci. $21,9724-9732$.

McCurry, C.L., Shepherd, J.D., Tropea, D., Wang, K.H., Bear, M.F., and Sur, M. (2010). Loss of Arc renders the visual cortex impervious to the effects of sensory experience or deprivation. Nat. Neurosci. 13, 450457.

Messaoudi, E., Kanhema, T., Soulé, J., Tiron, A., Dagyte, G., da Silva, B., and Bramham, C.R. (2007). Sustained Arc/Arg3.1 synthesis controls long-term potentiation consolidation through regulation of local actin polymerization in the dentate gyrus in vivo. J. Neurosci. 27, 10445-10455.

Minatohara, K., Akiyoshi, M., and Okuno, H. (2015). Role of Immediate-Early Genes in Synaptic Plasticity and Neuronal Ensembles Underlying the Memory Trace. Front. Mol. Neurosci. 8, 78. 
613

614

615

616

617

618

619

620

621

622

623

624

625

626

627

628

629

630

631

632

633

634

635

636

637

638

639

640

Mo, J., Kim, C.-H., Lee, D., Sun, W., Lee, H.W., and Kim, H. (2015). Early growth response 1 (Egr-1) directly regulates GABA receptor $\alpha 2, \alpha 4$, and $\theta$ subunits in the hippocampus. J. Neurochem. 133, 489500.

Morgan, J.I., Cohen, D.R., Hempstead, J.L., and Curran, T. (1987). Mapping patterns of c-fos expression in the central nervous system after seizure. Science (80-. ). 237, 192-197.

Okuno, H., Akashi, K., Ishii, Y., Yagishita-Kyo, N., Suzuki, K., Nonaka, M., Kawashima, T., Fujii, H., Takemoto-Kimura, S., Abe, M., et al. (2012). Inverse synaptic tagging of inactive synapses via dynamic interaction of Arc/Arg3.1 with CaMKIIß. Cell 149, 886-898.

Paxinos, G., and Franklin, K.B.J. (2013). Paxinos and Franklin's the mouse brain in stereotaxic coordinates (Academic Press).

Petreanu, L., Mao, T., Sternson, S.M., and Svoboda, K. (2009). The subcellular organization of neocortical excitatory connections. Nature 457, 1142-1145.

Ploski, J.E., Pierre, V.J., Smucny, J., Park, K., Monsey, M.S., Overeem, K.A., and Schafe, G.E. (2008). The activity-regulated cytoskeletal-associated protein (Arc/Arg3.1) is required for memory consolidation of pavlovian fear conditioning in the lateral amygdala. J. Neurosci. 28, 12383-12395.

Ramírez-Amaya, V., Vazdarjanova, A., Mikhael, D., Rosi, S., Worley, P.F., and Barnes, C.A. (2005). Spatial Exploration-Induced Arc mRNA and Protein Expression: Evidence for Selective, Network-Specific Reactivation. J. Neurosci. 25, 1761-1768.

Ramirez, S., Liu, X., Lin, P.-A., Suh, J., Pignatelli, M., Redondo, R.L., Ryan, T.J., and Tonegawa, S. (2013). Creating a false memory in the hippocampus. Science 341, 387-391.

Reijmers, L.G., Perkins, B.L., Matsuo, N., and Mayford, M. (2007). Localization of a stable neural correlate of associative memory. Science 317, 1230-1233.

Rial Verde, E.M., Lee-Osbourne, J., Worley, P.F., Malinow, R., and Cline, H.T. (2006). Increased Expression of the Immediate-Early Gene Arc/Arg3.1 Reduces AMPA Receptor-Mediated Synaptic Transmission. Neuron 52, 461-474.

Rosen, K.M., McCormack, M.A., Villa-Komaroff, L., and Mower, G.D. (1992). Brief visual experience induces immediate early gene expression in the cat visual cortex. Proc. Natl. Acad. Sci. U. S. A. 89, 54375441. 
641

642

643

644

645

646

647

648

649

650

651

652

653

654

655

656

657

658

659

660

661

662

663

664

665

666

667

668

Saleem, A.B., Ayaz, A., Jeffery, K.J., Harris, K.D., and Carandini, M. (2013). Integration of visual motion and locomotion in mouse visual cortex. Nat. Neurosci. 16, 1864-1869.

Shepherd, J.D., and Bear, M.F. (2011). New views of Arc, a master regulator of synaptic plasticity. Nat. Neurosci. 14, 279-284.

Shepherd, J.D., Rumbaugh, G., Wu, J., Chowdhury, S., Plath, N., Kuhl, D., Huganir, R.L., and Worley, P.F. (2006). Arc/Arg3.1 Mediates Homeostatic Synaptic Scaling of AMPA Receptors. Neuron 52, 475-484.

Steward, O., Matsudaira Yee, K., Farris, S., Pirbhoy, P.S., Worley, P., Okamura, K., Okuno, H., and Bito, H. (2018). Delayed degradation and impaired dendritic delivery of intron-lacking EGFP-Arc/Arg3.1 mRNA in EGFP-Arc transgenic mice. Front. Mol. Neurosci. 10.

Tagawa, Y., Kanold, P.O., Majdan, M., and Shatz, C.J. (2005). Multiple periods of functional ocular dominance plasticity in mouse visual cortex. Nat. Neurosci. 8, 380-388.

Tzingounis, A. V., and Nicoll, R.A. (2006). Arc/Arg3.1: Linking Gene Expression to Synaptic Plasticity and Memory. Neuron 52, 403-407.

Vazdarjanova, A., Ramirez-Amaya, V., Insel, N., Plummer, T.K., Rosi, S., Chowdhury, S., Mikhael, D., Worley, P.F., Guzowski, J.F., and Barnes, C.A. (2006). Spatial exploration induces ARC, a plasticity-related immediate-early gene, only in calcium/calmodulin-dependent protein kinase II-positive principal excitatory and inhibitory neurons of the rat forebrain. J. Comp. Neurol. 498, 317-329.

Veyrac, A., Besnard, A., Caboche, J., Davis, S., and Laroche, S. (2014). The Transcription Factor Zif268/Egr1, Brain Plasticity, and Memory. Prog. Mol. Biol. Transl. Sci. 122, 89-129.

Wang, K.H., Majewska, A., Schummers, J., Farley, B., Hu, C., Sur, M., and Tonegawa, S. (2006). In vivo two-photon imaging reveals a role of arc in enhancing orientation specificity in visual cortex. Cell 126, 389-402.

Waung, M.W., Pfeiffer, B.E., Nosyreva, E.D., Ronesi, J.A., and Huber, K.M. (2008). Rapid Translation of Arc/Arg3.1 Selectively Mediates mGluR-Dependent LTD through Persistent Increases in AMPAR Endocytosis Rate. Neuron 59, 84-97.

Weng, F.-J., Garcia, R.I., Lutzu, S., Alviña, K., Zhang, Y., Dushko, M., Ku, T., Zemoura, K., Rich, D., GarciaDominguez, D., et al. (2018). Npas4 Is a Critical Regulator of Learning-Induced Plasticity at Mossy FiberCA3 Synapses during Contextual Memory Formation. Neuron. 
669 Xie, H., Liu, Y., Zhu, Y., Ding, X., Yang, Y., and Guan, J.-S. (2014). In vivo imaging of immediate early gene

670 expression reveals layer-specific memory traces in the mammalian brain. Proc. Natl. Acad. Sci. 111,

$671 \quad 2788-2793$.

672 Yamada, Y., Hada, Y., Imamura, K., Mataga, N., Watanabe, Y., and Yamamoto, M. (1999). Differential

673 expression of immediate-early genes, c-fos and zif268, in the visual cortex of young rats: effects of a

674 noradrenergic neurotoxin on their expression. Neuroscience 92, 473-484.

675 Yap, E.-L., and Greenberg, M.E. (2018). Activity-Regulated Transcription: Bridging the Gap between

676 Neural Activity and Behavior. Neuron 100, 330-348.

677 Yasoshima, Y., Sako, N., Senba, E., and Yamamoto, T. (2006). Acute suppression, but not chronic genetic

678 deficiency, of c-fos gene expression impairs long-term memory in aversive taste learning. Proc. Natl.

679 Acad. Sci. U. S. A. 103, 7106-7111.

680 Yassin, L., Benedetti, B.L., Jouhanneau, J.S., Wen, J.A., Poulet, J.F.A., and Barth, A.L. (2010). An

681 Embedded Subnetwork of Highly Active Neurons in the Neocortex. Neuron 68, 1043-1050.

682 Zmarz, P., and Keller, G.B. (2016). Mismatch Receptive Fields in Mouse Visual Cortex. Neuron 92, 766-

683772. 